\title{
Does distance matter? Geographical variation in GP out-of-hours service use: an observational study
}

\author{
Joanne Turnbull, David Martin, Val Lattimer, Catherine Pope and David Culliford
}

\begin{abstract}
Background

GP cooperatives are typically based in emergency primary care centres, and patients are frequently required to travel to be seen. Geography is a key determinant of access, but little is known about the extent of geographical variation in the use of out-ofhours services.
\end{abstract}

Aim

To examine the effects of distance and rurality on rates of out-of-hours service use.

\section{Design of study}

Geographical analysis based on routinely collected data on telephone calls in June $(n=14482)$ and December $(n=19747)$, and area-level data.

\section{Setting}

Out-of-hours provider in Devon, England serving nearly 1 million patients.

\section{Method}

Straight-line distance measured patients' proximity to the primary care centre. At area level, rurality was measured by Office for National Statistics Rural and Urban Classification (2004) for output areas, and deprivation by The Index of Multiple Deprivation (2004).

\section{Results}

Call rates decreased with increasing distance: 172 (95\% confidence interval $[\mathrm{Cl}]=170$ to 175 ) for the first (nearest) distance quintile, $162(95 \% \mathrm{Cl}=159$ to 165$)$ for the second, and $159(95 \% \mathrm{Cl}=156$ to 162$)$ per thousand patients/year for the third quintile. Distance and deprivation predicted call rate. Rates were highest for urban areas and lowest for sparse villages and hamlets. The greatest urban/rural variation was in patients aged 0-4 years. Rates were higher in deprived areas, but the effect of deprivation was more evident in urban than rural areas.

\section{Conclusion}

There is geographical variation in out-of-hours service use. Patients from rural areas have lower call rates, but deprivation appears to be a greater determinant in urban areas. Geographical barriers must be taken into account when planning and delivering services.

\section{Keywords}

distance; general practice; geographic factors; health services accessibility; out-of-hours medical care; rural health.

\section{INTRODUCTION}

Improving patient access to primary care continues to be a priority for the UK government. ${ }^{1,2}$ Geography is one key determinant of access; it may present barriers of cost, time, and inconvenience for patients consulting their GP out of hours, but the effects of distance and rurality are sometimes overlooked. ${ }^{3}$ Following the introduction of a new GP contract in 2004 (where GPs were able to opt out of 24-hour responsibility for their patients), ${ }^{4}$ there was a significant change in the configuration of out-of-hours provision. Primary care trusts (now responsible for commissioning out-of-hours services) may have contracts with several providers. Out-of-hours care remains a contentious issue, with concerns over fragmented services, quality, and increasing costs of provision. ${ }^{5}$ Although different models of out-of-hours care exist, GP-led cooperatives have remained the standard service in many areas and are typically based in emergency primary care centres. ${ }^{6}$ Patients are frequently required to travel to be seen, raising concerns over poorer access for patients living further away from such services. ${ }^{7,8}$ Out-of-hours care is often exclusively accessed by telephone, which acts as a barrier for some groups, ${ }^{9}$ but potentially facilitates access for those living at greater distances from services.

J Turnbull, MSc, research fellow; V Lattimer; PhD, professor; C Pope, PhD, reader; School of Nursing \& Midwifery; D Martin, PhD, professor, School of Geography; D Culliford; MSc, medical statistician, Research \& Development Support Unit, School of Medicine, Southampton General Hospital, University of Southampton, Southampton.

Address for correspondence

Joanne Turnbull, University of Southampton, School of Nursing \& Midwifery, University Road, Highfield, Southampton, SO17 1BJ. E-mail: j.c.turnbull@soton.ac.uk

Submitted: 16 August 2007; Editor's response: 25 September 2007; final acceptance: 21 April 2008.

(o) British Journal of General Practice 2008; 58: 471-477.

DOI: 10.3399/bjgp08X319431 


\section{How this fits in}

The delivery and organisation of out-of-hours services raises concerns about access (for example, patients are often required to be seen at primary care centres). This is the first study to present rates of out-of-hours calls by deprivation, distance, and rurality. Geographical barriers appear to be important in patients' use of out-of-hours services.

Previous UK studies, including a large study of 20 GP cooperatives, ${ }^{10}$ have reported rates of out-ofhours use by social and demographic characteristics. Other studies have demonstrated that patients who live further away have lower rates of use of daytime general practice, ${ }^{11-13}$ emergency department, ${ }^{14-16}$ and emergency hospital admissions. ${ }^{17}$ Lower rates of daytime GP consultation are reported for patients in 'rural' areas, ${ }^{18}$ although not universally. ${ }^{19}$ Few studies have examined geographical variation in out-of-hours service use. The notable exception is a Northern Irish study that found patients who lived at greater road distance (and travel time) from primary care centres had fewer contacts with out-of-hours services..$^{20}$ The study did not include a measure of rurality. A further study in Ireland reported higher contact rates for 'rural' cooperatives compared to 'urban' ones, ${ }^{21}$ perhaps unexpectedly. 'Rural' and 'urban' were selfreported rather than measured objectively.

This paper reports the first study to present rates of out-of-hours calls by deprivation, distance, and rurality, with a population base of nearly 1 million patients in Devon, England, using objective measures of geographical access.

\section{METHOD}

This observational study was a geographical analysis based on routinely collected data on telephone calls, patient population data from general practices, and area-level data for Devon.

\section{Setting}

The county of Devon, approximately $6636 \mathrm{~km}^{2},{ }^{22}$ was selected for study because it provided a range of different geographical area types, including major cities (Plymouth and Exeter), and accessible rural and remote rural areas. One out-of-hours provider covered $81 \%$ of the county population, ensuring patients from different geographical area types would receive care from the same provider. A GP-led service of over 500 members provided care for 928725 registered patients and operated 19 primary care centres at district or community hospitals; nine opened during weekdays and weekends, 10 additional centres opened only on weekends and bank holidays, and two of these opened only on Saturday mornings. Additionally, the organisation provided a message-handling service for a small number of subscribing GPs (covering $8 \%$ of the population), where call answering and handling was provided but the local service provided triage and consultation.

\section{Data}

Individual-level service activity data. The analysis in this study is based on 34229 patient calls received by the service in June $(n=14482)$ and December $(n=$ 19 747) 2003. These months represent summer and winter activity and include a major bank holiday period. Anonymised details of calls included the patients' age and sex, date and time of call, postcode, and 'call outcome' (describing how patients were managed, commonly by primary care centre attendance, GP telephone advice, or home visit).

\section{Area-level data}

Measures of deprivation, distance, and rurality were matched to patient activity data where patients' postcode was complete ( $92 \%$ of calls). The Index of Multiple Deprivation 2004 of super output areas (SOAs) (ID2004) was used to create quintiles of deprivation by dividing the population of SOAs in Devon (not national quintiles). ${ }^{23}$ The straight-line distance from patients' addresses to their nearest open primary care centre, based on time and the day of the week of their call, was calculated. The cut-off points for the quintiles are: first (nearest), 0-2.1 km; second, 2.2-3.7 km; third, 3.8-5.3 km; fourth, $5.4-9.9 \mathrm{~km}$; and fifth (furthest), $\geq 10 \mathrm{~km}$. Rurality was measured by the Office for National Statistics (ONS) Rural and Urban Area Classification (2004) for output areas (OAs). ${ }^{24}$ Each $\mathrm{OA}$ is classified by the following four settlement types: urban; small town and fringe; village; hamlets and isolated dwellings. Each is allocated to either a 'sparse' or 'less sparse' context, giving eight categories.

\section{Analysis}

Data were analysed using SPSS (version 14) and Microsoft Office Excel $^{\otimes}$ 2003. The Kruskal-Wallis method was used to examine differences between groups. Age/sex-specific and age/sex-standardised call rates (per 1000 patients/year) with 95\% confidence intervals (Cls) were calculated by deprivation quintile, distance quintile, and ONS rural/urban category. To estimate annual rates, the number of calls for June and December were averaged and the resulting monthly aggregate was multiplied by 12 . This calculation was checked against annual call volume figures, which demonstrated this assumption was an accurate 
reflection. Call rates were directly standardised to the out-of-hours population of a study by Salisbury et al covering 4.6 million patients (707 198 calls) across the UK, ${ }^{10}$ providing a proxy 'English population'.

The population denominator for calculating rates was derived from: registered age/sex GP patient lists; and Census 2001 population estimates at OA level (used in the geographical analysis), and at SOA level (deprivation analysis). For all analysis, the population denominator was adjusted for populations that were covered by alternative out-ofhours arrangements, by subtracting practice list sizes of non-members from the population totals. Multiple linear regression was undertaken to examine variation in use, based on 705 SOAs in Devon. Call rates for SOAs (treated as a continuous variable) were taken as the dependent variable, with distance and deprivation as possible explanatory factors. This analysis reflects the approach taken by a similar study of out-of-hours service use..$^{20}$

A proportion of calls had some missing information: age, $n=3151$ (9.2\%); sex, $n=585$ (1.7\%); and postcode, $n=3204$ (9.4\%). Data are missing for one or more of these variables in $18 \%$ of cases; therefore there is some underestimation in the standardised rates. The most likely reason for missing postcode data was that callers either did not know their postcode or they lived in newly built houses which do not have registered postcodes. It is assumed there is no bias in missing data by geographical location; therefore a complete case analysis was performed. Message handling service calls were included in the deprivation and rural/urban analysis to give overall rates of service use, but were excluded from the distance analysis since these calls would not receive treatment at the primary care centres.

\section{RESULTS}

Of 34229 calls, 18220 (53.3\%) were weekend calls and 3055 (8.9\%) bank holiday calls. Overall, message handling service calls accounted for $8.5 \%$ of the workload (2906 calls). Of 28116 calls with complete postcode, age, and sex data, 20369 patients (86\%) called once, 2505 (11\%) called twice, and 750 (3\%) called three times or more (calls with the same postcode, age, and sex were assumed to be the same person). The standardised call rate for females was $185(95 \% \mathrm{Cl}=184$ to 186$)$ per 1000 patients/year and 142 per 1000 patients/year $(95 \% \mathrm{Cl}=141$ to 143$)$ for males. The highest rate was found in the age range 0-4 years, males 619 per 1000 patients/year $(95 \% \mathrm{Cl}=613$ to 625$)$ and females 561 per 1000 patients/year $(95 \% \mathrm{Cl}=554$ to 567$)$. Deprivation exerted a strong effect, with higher rates for each quintile of increasing deprivation (Table 1).
Table 1. Age/sex-standardised rates (per 1000 patients/year) of out-of-hours calls by deprivation.

\begin{tabular}{lccc} 
ID2004 quintile & Number of calls & $\begin{array}{c}\text { Patient } \\
\text { population }^{\text {a }}\end{array}$ & $\begin{array}{c}\text { Age/sex-standardised } \\
\text { rate (95\% Cl) }\end{array}$ \\
\hline 1 (most deprived) & 6502 & 173966 & $200(198$ to 201) \\
\hline 2 & 5586 & 169963 & $175(173$ to 177$)$ \\
\hline 3 & 5291 & 201087 & $141(139$ to 142$)$ \\
\hline 5 (least deprived) & 5400 & 193067 & $149(147$ to 150$)$ \\
\hline Total & 5145 & 207881 & $128(127$ to 130$)$ \\
\hline
\end{tabular}

Cases with compete age and sex data ( $\mathrm{n}=27$ 924); 192 cases were covered by out-ofhours service provider but patients lived in neighbouring counties so were excluded from the analysis. Data on postcode, age, or sex were missing for 6113 cases. ${ }^{a}$ Patient population based on 2001 Office for National Statistics Census estimates.

\section{Distance}

Most calls were from patients who lived within $5 \mathrm{~km}$ of their nearest primary care centre; $61 \%$ on weekdays, $72 \%$ at weekends and $81 \%$ on Saturday mornings (this variation reflects the fact that more primary care centres were open at the weekend). If invited to attend the primary care centre, weekend callers would be required to travel $3.3 \mathrm{~km}$ (interquartile range [IQR] 1.5-6.8 km) compared to $4.9 \mathrm{~km}$ (IQR 2.2-10.2 km) for weekday callers $\left(\chi^{2}=\right.$ 1221.2, $P<0.001)$. Patients in the most deprived quintile were a median distance of $2.5 \mathrm{~km}$ (IQR $1.3-4.7 \mathrm{~km}$ ) away from the primary care centre, increasing to $5.0 \mathrm{~km}$ (IQR 2.2-9.0 km) for the least deprived quintile $\left(\chi^{2}=2193.69, P<0.001\right)$. Overall, out-of-hours service use decreased with increasing distance, with call rates of $172(95 \% \mathrm{Cl}=170$ to 175$)$ for the first (nearest) distance quintile, $162(95 \% \mathrm{Cl}=$ 159 to 165$)$ for the second, and $159(95 \% \mathrm{Cl}=156$ to 162) for the third quintile (Table 2).

The regression model of call rates at SOA level against distance gave a parameter estimate of -3.17 (95\% Cl $=-4.02$ to $-2.32, P<0.001)$. This can be interpreted as a reduction in the SOA call rate per 1000 patients/year of 3.17 for each unit kilometre of straight-line distance. After adjusting for deprivation,

\section{Table 2. Age/sex-standardised call rate (per 1000} patients/year) by distance quintile.

\begin{tabular}{lccc} 
Distance quintile & Number of calls & $\begin{array}{c}\text { Patient } \\
\text { population }\end{array}$ & $\begin{array}{c}\text { Age/sex-standardised } \\
\text { rate (95\% Cl) }\end{array}$ \\
\hline 1 (nearest) & 6707 & 203637 & 172 (170 to 175) \\
\hline 2 & 5693 & 185992 & 162 (159 to 165) \\
\hline 3 & 4956 & 171202 & 159 (156 to 162) \\
\hline 4 & 4660 & 161290 & 152 (149 to 156) \\
\hline 5 (furthest) & 3895 & 133640 & 155 (152 to 158) \\
\hline Total & 25911 & 855761 & \\
\hline
\end{tabular}

apatient population based on 2001 Office for National Statistics Census estimates. The patient population excludes populations covered by message handling services. 


\begin{tabular}{|c|c|c|c|c|}
\hline Model & Variables & $\begin{array}{l}\text { Unstandardised } \\
\text { co-efficient (SE) }\end{array}$ & $t$ & $P$-value \\
\hline All & $\begin{array}{l}\text { Distance from PCC } \\
\text { ID2004 score }\end{array}$ & $\begin{array}{c}-2.80(0.43) \\
0.78(0.20)\end{array}$ & $\begin{array}{c}-6.37 \\
3.91\end{array}$ & $\begin{array}{l}<0.001 \\
<0.001\end{array}$ \\
\hline Males & $\begin{array}{l}\text { Distance from PCC } \\
\text { ID2004 score }\end{array}$ & $\begin{array}{l}-2.29(0.45) \\
0.40(0.20)\end{array}$ & $\begin{array}{c}-5.15 \\
1.96\end{array}$ & $\begin{array}{c}<0.001 \\
0.05\end{array}$ \\
\hline Females & $\begin{array}{l}\text { Distance from PCC } \\
\text { ID2004 score }\end{array}$ & $\begin{array}{c}-3.18(0.53) \\
1.16(0.24) \\
\end{array}$ & $\begin{array}{c}-6.00 \\
4.84 \\
\end{array}$ & $\begin{array}{l}<0.001 \\
<0.001\end{array}$ \\
\hline $0-4$ years & $\begin{array}{l}\text { Distance from PCC } \\
\text { ID2004 score }\end{array}$ & $\begin{array}{c}-8.78(2.30) \\
2.31(1.03)\end{array}$ & $\begin{array}{c}-3.81 \\
2.24\end{array}$ & $\begin{array}{c}<0.001 \\
0.025\end{array}$ \\
\hline 5-24 years & $\begin{array}{l}\text { Distance from PCC } \\
\text { ID2004 score }\end{array}$ & $\begin{array}{c}-1.84(0.46) \\
0.51(0.21)\end{array}$ & $\begin{array}{c}-3.99 \\
2.37 \\
\end{array}$ & $\begin{array}{l}<0.001 \\
0.018 \\
\end{array}$ \\
\hline 25-64 years & $\begin{array}{l}\text { Distance from PCC } \\
\text { ID2004 score }\end{array}$ & $\begin{array}{c}-1.87(0.37) \\
1.14(0.17) \\
\end{array}$ & $\begin{array}{c}-5.05 \\
6.80 \\
\end{array}$ & $\begin{array}{l}<0.001 \\
<0.001\end{array}$ \\
\hline$\geq 65$ years & $\begin{array}{l}\text { Distance from PCC } \\
\text { ID2004 score }\end{array}$ & $\begin{array}{c}-3.65(1.01) \\
1.09(0.48)\end{array}$ & $\begin{array}{c}-3.60 \\
2.28\end{array}$ & $\begin{array}{c}<0.001 \\
0.023\end{array}$ \\
\hline
\end{tabular}

$P C C=$ primary care centre; $S E=$ standard error.

the parameter estimate for distance reduces slightly to $-2.80(95 \% \mathrm{Cl}=-3.66$ to $-1.93, P<0.001)$ (Table 3$)$.

Similar results were observed when undertaking separate analyses for males and females and for different age groups. Although the effect of distance is significant, the effect size is quite small.

When only distance was included in the model, the variable explains only $7.1 \%$ of the variation in rates, increasing to $9.1 \%$ when deprivation is added; therefore the predictive value of the model is low.

\section{Rurality}

Two-thirds (66.5\%) of calls were from 'less sparse urban' OAs, $12.7 \%$ from 'less sparse town and fringe' OAs, $7.7 \%$ from 'less sparse villages' and $4.6 \%$ from 'less sparse hamlets and isolated dwellings'. Small proportions of calls were from patients living in 'sparse' OAs (1.3-3.2\%). The most deprived OAs in

\section{Table 4. Age/sex standardised rates (per 1000 patients per} year) of out-of-hours service use by rural/urban area.

\begin{tabular}{lcccc} 
Settlement type & Context & $\begin{array}{c}\text { Number } \\
\text { of calls }\end{array}$ & Population $^{\text {a }}$ & $\begin{array}{c}\text { Age/sex- } \\
\text { standardised } \\
\text { rate }(95 \% \text { Cl) }\end{array}$ \\
\hline Urban & Sparse & 382 & 10469 & $197(190$ to 205) \\
\hline Town and fringe & Sparse & 811 & 19365 & $203(198$ to 209) \\
& Less sparse & 3580 & 131535 & $139(138$ to 141$)$ \\
\hline Village & Sparse & 591 & 25240 & $130(126$ to 134) \\
\hline Hamlet and & Less sparse & 2144 & 94508 & $126(120$ to 124) \\
isolated dwellings & Sparse & 495 & 27333 & $106(103$ to 110) \\
\hline Total & Less sparse & 1288 & 59924 & $120(117$ to 122) \\
\hline
\end{tabular}

Data on postcode, age or sex were missing for 6113 cases; 192 were excluded as they were outside the Devon area. ${ }^{\text {a }}$ Population estimates from Office for National Statistics 2001 Census.
Devon were exclusively urban. Overall, call rates decreased steadily with increasing rurality (Table 4). The highest rates were from urban areas, and the lowest rates from the most remote OAs ('sparse villages' and 'sparse hamlets/isolated dwellings'). Age/sex-specific call rates showed that 0-4-year-old patients had more variation than any other age group (Figure 1), with calls rates being significantly higher in urban than rural areas (with the exception of females from 'urban sparse' OAs, although this category covers a small population and may be subject to greater variability). In urban areas, call rates were much higher for those in more deprived quintiles, declining steadily with decreasing deprivation (Table 5). Town/fringe and village OAs showed no obvious relationship with deprivation (this comparison is made slightly difficult since no rural OAs are in the most deprived quintile).

\section{DISCUSSION}

\section{Summary of main findings}

There was strong evidence of distance and rurality effects on out-of-hours service use. Patients who lived at greater distances or in rural areas had lower call rates. There was a differential effect by age group, with greatest rural/urban variation among children aged 0-4 years and, to a lesser extent, patients aged $\geq 75$ years. Patients from deprived areas made more calls but the effect of deprivation was more evident in urban than rural areas, suggesting that behaviour is influenced by deprivation for patients in urban areas, while in rural areas, distance rather than deprivation may influence the decision to call.

\section{Strengths and limitations of the study}

This is the first study to present rates of out-of-hours calls by deprivation, distance, and rurality in the same study. It attempted to control for the confounding effects of deprivation in the utilisation rates and rurality, although the study was primarily aimed at investigating geographic not socioeconomic effects. Deprivation is an inevitable confounder when examining geographical aspects of health service use, and many previous studies have not controlled for its effects. ${ }^{25}$ One difficulty lies in combining key variables that are only available at different geographical scales (for example, postcoded patient records and SOA-level deprivation indices). Straight-line distance and ONS rural/urban classification provide only two, albeit complementary, geographical access measures. ${ }^{26}$

The effect of using other measures is unknown. Straight-line distance has been widely used in healthcare access studies, ${ }^{13}$ and has the advantage of straightforward calculation for large numbers of cases. Its drawback is that it does not take into 

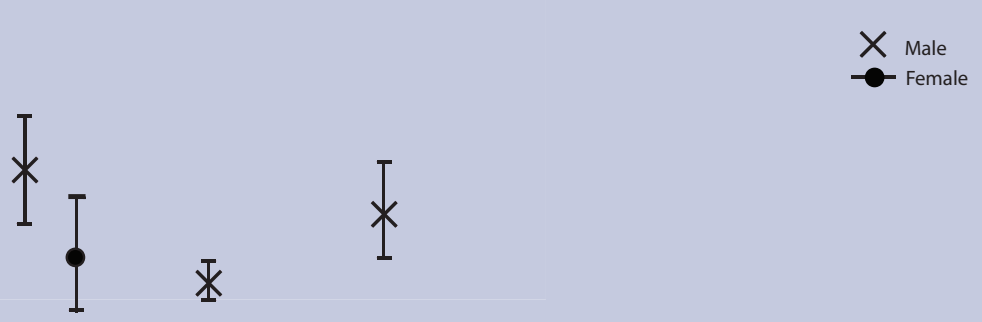

Female

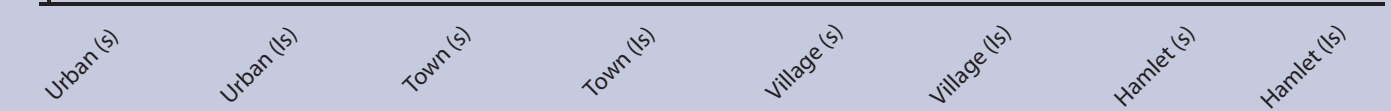

Rural/Urban classification

$\mathrm{s}=$ sparse

Is = less sparse

account variations in transport network density due to physical barriers such as mountains or coastline. Road distance and travel time may arguably better reflect patients' experiences of access, particularly in rural areas, ${ }^{27}$ but are more complex to calculate and assume access to car transport. Straight-line distance has been shown to correlate well with more complex measures such as travel time. ${ }^{28}$ Few patients are likely to be reallocated between the distance quintiles used here.

The study looked at one geographical area and service provider in England. Pockets of deprivation exist, but the area is relatively affluent compared with much of the UK and has comparatively good levels of
Figure 1. Rates $(95 \% \mathrm{Cl})$ of out-of-hours service use for 0-4 year olds by geographic area.

Table 5. Age/sex-standardised rates by deprivation and by rural/urban category.

\begin{tabular}{|c|c|c|c|c|}
\hline Rural/urban category & Deprivation quintile & Number of calls & Patient population & $\begin{array}{c}\text { Age/sex standardised } \\
\text { rate }(95 \% \mathrm{Cl})\end{array}$ \\
\hline \multirow[t]{5}{*}{ Urban } & 1 (most deprived) & 6488 & 172933 & 200 (199 to 202) \\
\hline & 2 & 4158 & 115728 & 191 (189 to 193 ) \\
\hline & 3 & 2686 & 94178 & 151 (149 to 153 ) \\
\hline & 4 & 2637 & 84674 & 164 (162 to 167$)$ \\
\hline & 5 (least deprived) & 3061 & 126780 & 126 (125 to 128 ) \\
\hline \multirow[t]{5}{*}{ Town and fringe } & 1 (most deprived) & 0 & 0 & - \\
\hline & 2 & 809 & 23199 & 122 (119 to 126$)$ \\
\hline & 3 & 1025 & 35488 & 165 (162 to 168$)$ \\
\hline & 4 & 1176 & 47918 & 142 (139 to 145$)$ \\
\hline & 5 (least deprived) & 1381 & 49700 & 122 (118 to 126$)$ \\
\hline \multirow{5}{*}{$\begin{array}{l}\text { Village, hamlet and } \\
\text { isolated dwellings }\end{array}$} & 1 (most deprived) & 0 & 0 & - \\
\hline & 2 & 633 & 32069 & 109 (106 to 113$)$ \\
\hline & 3 & 1580 & 71421 & 122 (120 to 125$)$ \\
\hline & 4 & 1587 & 60475 & 142 (139 to 145$)$ \\
\hline & 5 (least deprived) & 703 & 31401 & 125 (121 to 128 ) \\
\hline Total & & 27924 & 945964 & \\
\hline
\end{tabular}


health. ${ }^{23}$ Also, there are no substantial ethnic minority populations. Common to many studies using routine service activity data, some age, sex, and postcode data were missing, so call rates are an underestimation. Utilisation as a proxy for 'access' or 'need' may be problematic, ${ }^{29}$ since individuals with equal 'need' may not make equal use of health care ('barriers' may deter access). However, one can argue that utilisation is important, since living in an area with ample healthcare resources is of little importance if the resources are inaccessible or of low quality. ${ }^{30}$

Multilevel modelling could potentially be applied to a dataset of this type but there were difficulties in using such an approach here. The anonymised dataset did not provide a unique patient identification number or details to allow grouping by GP. The configuration of primary care centres open to patients varied by time and day of week, and thus did not provide a stable modelling framework. By contrast, the study focused on key aspects of rurality and deprivation, previously found to be important and providing a meaningful classification of the study population at all times. Importantly, the methods of analysis used allow comparison with other, similar, key studies. ${ }^{10,20,31}$

\section{Comparison with existing literature}

Females, young children, older people, and those from the most deprived areas were the highest service users. Call rates were within the ranges found elsewhere, ${ }^{10,20}$ and patterns of use by age, sex, and deprivation were consistent with previous studies. ${ }^{10,31}$ The suggestion that telephone access may potentially overcome physical barriers was not supported. The effects of increased distance on reduced out-ofhours service use reflect the findings of an earlier study. ${ }^{20}$ The present study suggested that rurality may present particular difficulties or disincentives for certain population groups (for example, parents with children aged 0-4 years), but further research is needed to examine why. People with the greatest need for care (for example, older people and deprived populations) are those most likely to have poorer access to transport. ${ }^{32}$ However, it is difficult to assess the extent to which geographical variation equates to inequity. Poorer geographical access may suppress demand for health services, resulting in lower levels of use, but not in inequity of opportunity for access.

\section{Implications for future research}

Geographical barriers appear to be an important determinant of the propensity with which people call GPs out of hours. A better understanding of patient access is important in planning services. Geographical barriers may lead to delays in help seeking, resulting in avoidable ill-health or mortality, and may have social and economic costs to individuals. Although the data in this study were collected prior to the introduction of the 2004 general medical services contract, the findings are still important since current out-of-hours care models commonly require patients to travel to a centre to be seen, following an initial telephone contact. Further research is needed to examine if newer models present their own unique geographical barriers. Patients' decisions to seek medical care are influenced by a range of factors, including symptoms, service organisation, and access. ${ }^{33}$ Evidence suggests that, other things being equal, patients' willingness to seek care declines with distance. ${ }^{34}$ Patients' decisions to consult out of hours require further research, which needs to include a range of complex, interlinked determinants, of which geography is one.

\section{Funding body}

$\mathrm{PhD}$ studentship funded by the University of Southampton Ethical approval

North \& East Devon REC (now Devon \& Torbay REC) (05/Q2102/71)

\section{Competing interests}

The authors have stated that there are none

Acknowledgements

Our thanks go to the staff at the out-of-hours provider for their involvement in organising and providing us with data and for their support of the study.

\section{Discuss this article}

Contribute and read comments about this article on the Discussion Forum: http://www.rcgp.org.uk/bjgp-discuss

\section{REFERENCES}

1. Department of Health. Raising standards for patients: new partnerships in out-of-hours care. An independent review commissioned by the Department of Health. London: HMSO, 2000.

2. Department of Health. The new NHS - modern, dependable. London: HMSO, 1997.

3. Goddard M, Smith P. Equity of access to health care services: theory and evidence from the UK. Soc Sci Med 2001; 53(9): 1149-1162.

4. British Medical Association. Investing in general practice: the new general medical services contract. London: British Medical Association, 2003.

5. House of Commons, Committee of Public accounts. The provision of out-of-hours care in England. London: The Stationery Office, 2007.

6. Hallam L, Henthorne K. Cooperatives and their primary care emergency centres: Organisation and impact: combined report on seven case studies. Health Technol Assess 1999; 3(7): 1-85.

7. Hallam L. Out of hours primary care. BMJ 1997; 314(7075): 157-158.

8. Munro J, Maheswaran R, Pearson T. Response to requests for general practice out of hours: geographical analysis in north west England. $J$ Epidemiol Community Health 2003; 57(9): 673-674.

9. Foster J, Dale J, Jessopp L. A qualitative study of older people's views of out-of-hours services. Br J Gen Pract 2001; 51(470): 719-723.

10. Salisbury C, Trivella M, Bruster S. Demand for and supply of out of hours care from general practitioners in England and Scotland: observational study based on routinely collected data. BMJ 2000; 320(7235): 618-621.

11. Whitehouse CR. Effect of distance from surgery on consultation rates in an urban practice. BMJ 1985; 290(6465): 359-362.

12. Haynes RM, Bentham CG. The effects of accessibility on general practitioner consultations, out-patient attendances and in-patient admissions in Norfolk, England. Soc Sci Med 1982; 16(5): 561-569.

13. Jones AP, Bentham G, Harrison BD, et al. Accessibility and health service utilization for asthma in Norfolk, England. J Public Health Med 1998; 20(3): 312-317.

14. Campbell JL. General practitioner appointment systems, patient satisfaction, and use of accident and emergency services - a study in one geographical area. Fam Pract 1994; 11(4): 438-445. 
15. Walsh M. Geographical factors and A\&E attendance. Nurs Stand 1990; 5(8): 28-31.

16. McKee CM, Gleadhill DN, Watson JD. Accident and emergency attendance rates: variation among patients from different general practices. Br J Gen Pract 1990; 40(333): 150-153.

17. Haynes R, Bentham G, Lovett A, Gale S. Effects of distances to hospital and GP surgery on hospital inpatient episodes, controlling for needs and provision. Soc Sci Med 1999; 49(3): 425-433.

18. Carr-Hill RA, Rice N, Roland M. Socioeconomic determinants of rates of consultation in general practice based on fourth national morbidity survey of general practices. BMJ 1996; 312(7037): 1008-1012.

19. Scottish Executive Environment and Rural Development Department Social Research Branch. Living in Scotland: an urban-rural analysis of the Scottish Household Survey. Edinburgh: Scottish Executive, 2003.

20. O’Reilly D, Stevenson M, McCay C, Jamison J. General practice out-ofhours service, variations in use and equality in access to a doctor: a cross-sectional study. Br J Gen Pract 2001; 51(469): 625-629.

21. Bury G, Dowling J, Janes D. General practice out-of-hours cooperatives — population contact rates. Ir Med J 2006; 99(3): 73-75.

22. Office for National Statistics. Geographic products: UK standard area measurements. http://www.statistics.gov.uk/geography/ sam.asp (accessed 20 May 2008).

23. Office of the Deputy Prime Minister. The English indices of deprivation 2004. (revised). London: ODPM, 2004. http://www.communities.gov.uk pub/446/Indicesofdeprivation2004revised_id1128446.pdf (accessed 24 Apr 2008).

24. Bibby P, Shepherd J. Developing a new classification of urban and rural areas for policy purposes - the methodology. London: Office for National Statistics, 2004. http://www.statistics.gov.uk/geography/ downloads/Methodology_Report.pdf (accessed 24 Apr 2008).

25. NHS Centre for Reviews and Dissemination. Concentration and choice in the provision of hospital services. The relationship between concentration, patient accessibility and the utilisation of services 1996. Report 8. Part III. York: The University of York, 1997.

26. Martin D, Roderick P, Brigham P, et al. The (mis)representation of rural deprivation. Environ Plan A 2000; 32(4): 735-751.

27. Jordan H, Roderick P, Martin D, Barnett S. Distance, rurality and the need for care: access to health services in South West England. Int I Health Geogr 2004; 3(1): 21.

28. Phibbs CS, Luft HS. Correlation of travel time on roads versus straight line distance. Med Care Res Rev 1995; 52(4): 532-542.

29. Oliver A, Mossialos E. Equity of access to health care: outlining the foundations for action. J Epidemiol Community Health 2004; 58(8): $655-658$.

30. Lin SJ, Crawford SY, Warren SJ. Potential access and revealed access to pain management medications. Soc Sci Med 2005; 60(8): 1881-1891.

31. Carlisle R, Groom LM, Avery AJ, et al. Relation of out of hours activity by general practice and accident and emergency services with deprivation in Nottingham: Longitudinal survey. BMJ 1998; 316(7130): 520-523.

32. Bentham G, Haynes R. Health, personal mobility and the use of health services in rural Norfolk. J Rural Stud 1985; 1(3): 231-239.

33. Farmer J, Iversen L, Campbell NC, et al. Rural/urban differences in accounts of patients' initial decisions to consult primary care. Health Place 2006; 12(2): 210-221.

34. Carr-Hill R, Place M, Posnett J. Access and the utilisation of healthcare services. In: Ferguson B, Sheldon T, Posnett J (eds). Concentration and choice in healthcare. London: Financial Times Healthcare; 1997: 39-40. 